\title{
Effects of local laser treatment on vulvovaginal atrophy among women with breast cancer: a prospective study with long-term follow-up
}

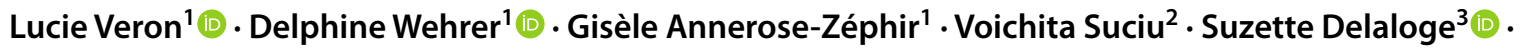 \\ Barbara Pistilli $^{3}$ (D) Dan Chaltiel ${ }^{4}$ (i) $\cdot$ Patricia Pautier $^{1}$ (D)
}

Received: 29 January 2021 / Accepted: 9 April 2021 / Published online: 23 April 2021

(c) The Author(s), under exclusive licence to Springer Science+Business Media, LLC, part of Springer Nature 2021

\begin{abstract}
Purpose Women with breast cancer (BC) often suffer from severe vulvovaginal atrophy (VVA) which ultimately leads to poor sexual and urinary quality of life. We conducted a prospective study among women with BC and VVA, in order to evaluate the long-term effect of laser therapy on VVA.

Methods Women with $\mathrm{BC}$ and VVA were proposed to have fractional microablative $\mathrm{CO}_{2}$ laser therapy (MonaLisaTouch ${ }^{\circledR}$, DEKA) once per month for 3 months. Efficacy of laser therapy was assessed at baseline, 6 months and 18 months after treatment, using Female Sexual Function Index (FSFI) score, Ditrovie score and vaginal pH. A pap smear was also performed and the epithelial maturation pattern was noted. Paired statistical tests were used to compare results between baseline, 6 months and 18 months.

Results 46 women with BC (median age [interquartile range] 56.5 years [47.0 - 59.4]) were included between May and October 2018. PH level slightly decreased over time (mean $\Delta$ at 18 months $-0.3, S D=0.7, p=0.02$ ) whereas maturation pattern on pap smear did not change. Sexual quality of life was significantly improved at 6 months and 18 months (mean $\Delta$ at 6 months 8.3, SD=6.2 $(p<0.0001)$ and mean $\Delta$ at 18 months 4.3, $S D=8.4(p=0.01))$. Ditrovie total score improved at 6 months (mean $\Delta-1.2, S D=2.7, p=0.01$ ) but returned to baseline afterwards. Side effects were very mild. Three women developed low (2)- and high (1)-grade HPV-linked cervical lesions during follow-up.

Conclusion Among women with $\mathrm{BC}$, fractional microablative $\mathrm{CO}_{2}$ laser is effective on the long term on VVA symptoms and gynaecological quality of life.

Trial registration number: ID-RCB 2018-A01500-55
\end{abstract}

Keywords Vulvovaginal atrophy $\cdot$ Vaginal laser therapy $\cdot$ Breast cancer

Lucie Veron

lucie.veron@gustaveroussy.fr

1 Department of Cancer Medicine/Gynecology, Gustave Roussy, 114 rue Edouard Vaillant, 94800 Villejuif, France

2 Departement of Laboratory Medicine and Pathology, Gustave Roussy, Villejuif, France

3 Department of Cancer Medicine/Breast Oncology, Gustave Roussy, Villejuif, France

4 Department of Biostatistics and Epidemiology, Gustave Roussy Cancer Campus, Villejuif, France

\section{Introduction}

Breast cancer is the most frequent cancer among women. Median age at diagnostic is around 60 but $25 \%$ of affected women are premenopausal [1]. Women with breast cancer (BC) often suffer from genitourinary syndrome of menopause (GSM), which includes severe vulvovaginal atrophy (VVA) and urinary symptoms, leading to dyspareunia and poor sexual and urinary quality of life [2]. These side effects are linked to endocrine deprivation in relation to chemotherapy, LHRH-agonists induced early menopause and endocrine therapy [3]. Endocrine therapy is prescribed for women with hormone receptor-positive breast cancer usually during 5 to 10 years [4-6] [7]. Thus, gynaecological side effects of BC treatments can last for many years or even for 
a lifetime [8], with many implications on sexual health [9], couple intimacy [10] and potentially on adherence to treatment such as endocrine therapy, which could have a real impact on survival [11].

GSM in women with BC is generally treated with nonhormonal local treatment, such as hyaluronic acid, but with moderate effect [12]. Vaginal laser therapy has been explored since several years to treat GSM and VVA in postmenopausal women, using either erbium or $\mathrm{CO}_{2}$ laser therapy, with the same efficacy [13-16]. However, this treatment has not yet been approved in the United States, due of lack of long-term follow-up studies on safety and efficacy. In Europe, laser device has obtained CE marking and can be used. To our knowledge, there is no current warning in Europe on laser treatment for vaginal atrophy. Laser treatment usually includes three laser sessions: one session per month for 3 months. Thereafter, a maintenance laser session can be proposed after several months or even a year, if efficacy decreases over time. Few studies have investigated the efficacy of vaginal laser in women with a previous history of breast cancer; most of them were retrospective or prospective cohorts [17-21]. In addition, the majority of studies stopped after 12 weeks of follow-up, so little is known on long-term effects and efficacy duration. We conducted a prospective single-centre study in women with $\mathrm{BC}$ to evaluate the long-term effect of fractional microablative $\mathrm{CO}_{2}$ laser therapy on VVA.

\section{Methods}

\section{Participant selection and treatment modalities}

This prospective and single-centre study was conducted in Gustave Roussy, Villejuif, France, a comprehensive cancer centre. The study was approved by a French Ethics Committee (ID-RCB No: 2018-A01500-55). Postmenopausal women with a history of $\mathrm{BC}$ and suffering from GSM were referred by their medical oncologists and proposed to receive fractional microablative $\mathrm{CO}_{2}$ laser therapy (MonaLisaTouch ${ }^{\circledR}$, DEKA) once per month for 3 months. Women gave oral consent to participate at the study. Menopause could be natural or treatment-induced. There were no restrictions regarding type and stage of $\mathrm{BC}$, age at $\mathrm{BC}$, type of $\mathrm{BC}$ treatment, time since end of treatment, and ongoing treatments. Contra-indications to laser therapy were ongoing gynaecological bleeding or infection, active genital herpes infection, pregnancy and severe genital prolapse. Laser parameters were those recommended by DEKA: laser energy was set at 26 to $40 \mathrm{~W}$ power with a dwell time of $1000 \mu \mathrm{s}$ and dot spacing of $1000 \mu \mathrm{m}$, with increasing stack at each session (1-3). Women were excluded if they had no breast cancer, if they had abnormal pap smear at baseline, if they were receiving chemotherapy at the beginning of the study or if they had received pelvic radiotherapy. A gynaecological exam was performed before each laser session to exclude any sign of vaginal infection. To prevent pain during gynaecological exam, soap could have been used to softly insert vaginal speculum.

\section{Study measures and outcomes}

Main objective was improvement in global, sexual and urinary quality of life in the intention-to-treat population. Secondary objectives were objective laser efficacy on vaginal health using vaginal $\mathrm{pH}$ and maturity pattern on cervical pap smear. At the time of the study, there were no predefined minimally clinical important difference definitions for any of these parameters in the available literature. Vaginal health was determined with $\mathrm{pH}$ level using a $\mathrm{pH}$ test strip on vaginal walls. The epithelial maturation pattern was evaluated on pap smear by a single anatomopathologist (V.S.), and classified as "mature", "subatrophy" or "atrophy". We chose to add a "subatrophy" category, in order to better assess maturation, as there are various degrees of atrophic changes in pap smear's interpretation [22, 23]. Global quality of life was assessed using the Short-Form 12 health survey (SF12) [24]. Sexual and urinary quality of life status were assessed using the Female Sexual Function Index (FSFI) score and the Ditrovie score. FSFI score investigates six different domains of sexual function: satisfaction, desire, lubrication, pain, arousal and orgasm. FSFI total score is scaled from 2 to 36,2 being worst sexual function [25, 26]. Ditrovie score is scaled from 1 to 5,1 being best urinary quality of life [27]. Measurements of vaginal health were performed during a medical appointment at baseline, before the last laser session (i.e. at 2 months) and at 6 months after the last laser session. Quality of life scores were assessed at baseline, before the last laser session, at 6 months and 18 months after the last laser session. Due to the COVID-19 pandemic, the fourth assessment of quality of life score (i.e. 18 months after the last laser session) was remotely. Treatment and measurements were unblinded. Comparisons were between baseline and 6 months and baseline and end of study. We used paired Wilcoxon test to compare $\mathrm{pH}$ levels, Ditrovie scores and FSFI scores, Macnemar test to compare epithelial maturation pattern and Student t-test to compare SF12 mental and physical components. Tests were computed using $\mathrm{R}$ software (version 4.0.2).

\section{Results}

\section{Study population}

Between May and December 2018, 51 women were screened for the study, of whom 46 were included (Fig. 1) and treated 
with a total of three vaginal laser therapy sessions (one session every month for 3 months). Forty-five women (97.8\%) received the full three laser therapies. Characteristics of the 46 women at inclusion are described in Table 1. Median age at inclusion was 56 (IQR [45.0 - 59.0]). The age of youngest woman was 35 and the oldest was 70 . The majority had localized BC ( $n=43,93.5 \%)$ and only three had metastatic BC. Thirty-three women (71\%) had received chemotherapy for BC. Thirty-six women $(78 \%)$ were taking endocrine therapy at inclusion (tamoxifen $n=6$, aromatase inhibitors $n=24$, aromatase inhibitors + LHRH agonist $n=6$ ). During the study, six women (17\%) stopped taking endocrine therapy (median time since last laser session, 9.5 months IQR [6.5-12]). Two women had a known history of lowgrade papillomavirus (HPV)-induced cervical lesions, but had normal follow-up result since several years before study entry. The median follow-up of the cohort was 19 months after the last laser session (min 16 months, max 23 months). Fifty-eight percent of women ( 21 of 36) asked for a maintenance session at the end of the study.

At inclusion, median pH was 7 (IQR [5.8-7.0]). Seventytwo percent of the pap smears were labelled as atrophic, $9 \%$ as subatrophic and $19 \%$ as mature. Median Ditrovie total score was 1.2 (IQR [1.0-1.6]), and median FSFI score was 9.5 (IQR [4.3-16.2]) (Table 1). Median mental component of SF12 score was 40.6 [33.8-50.5] and physical component score was 40.6 [35.1-47.0].

Before the last laser session (i.e. 2 months), vaginal $\mathrm{pH}$ was unchanged (median 7.0, IQR [5.8-7.0]), as well as

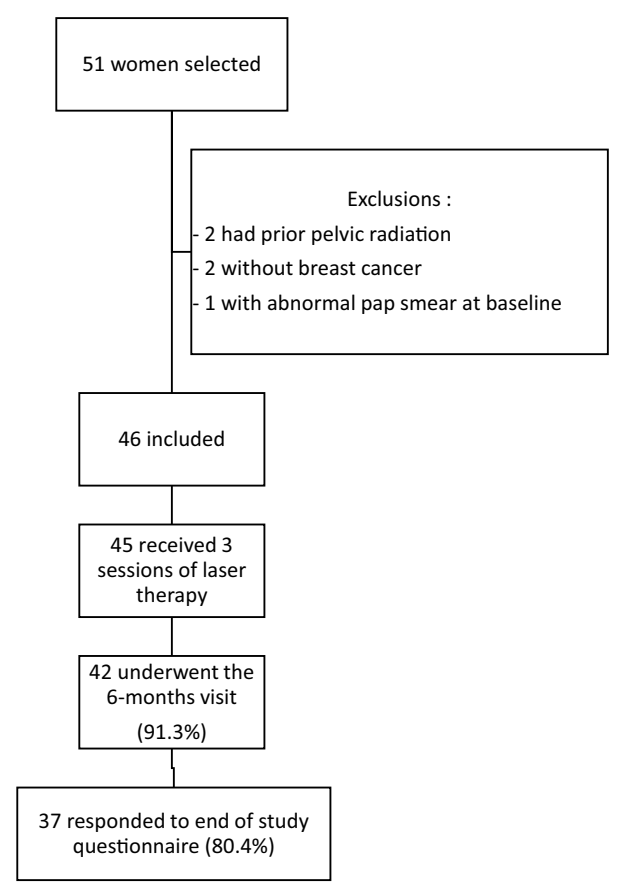

Fig. 1 Flow chart epithelial maturation pattern on pap smear (73.9\% of atrophy, $6.5 \%$ of subatrophy and $15.2 \%$ mature). Median Ditrovie total score was 1.1, IQR [1.0-1.4] and median FSFI total score was 20.5, IQR [14.0-25.2]. Median mental component of SF12 score was 39.6 [34.3-49.9] and physical component score was 42.0 [38.8-51.9].

\section{Impact of microablative $\mathrm{CO}_{2}$ laser therapy on sexual and urinary quality of life and vaginal health}

At 6 months, sexual and urinary quality of life both improved significantly (Ditrovie score: mean $\Delta=-1.2$, $S D=2.7, p=0.01$, FSFI score: mean $\Delta$ at 6 months $=8.3$, $S D=6.2, p<0.0001)$ ) (Fig. 2). Global quality of life was unchanged ( $p=0.1$ for mental component and $p=0.4$ for physical component). At the end of the study, FSFI score remained significantly increased compared to baseline (mean $\Delta$ at the end of study $=4.3, S D=8.4, p=0.01$ ) (Fig. 2), but tended to decrease over time between 6 months and end of study (Fig. 3). All 6 FSFI score domains increased at 6 months then decreased at end of study but remained above median baseline except for pain and desire domains, which decreased to baseline value (Table 2). Ditrovie total score did not differ from baseline (mean $\Delta=-0.6, S D=2.4$, $p=0.1$ ). Ditrovie score worsened between 6 months and end of study for women with urinary dysfunction (Fig. 4). Global quality of life remained unchanged ( $p=0.8$ for mental component and $p=0.3$ for physical component).

At 6 months, $\mathrm{pH}$ level decreased very slightly (mean $\Delta=-0.3, S D=0.7, p=0.02)$. Epithelial maturation pattern on cervical pap smear did not change (Macnemar test $p=1$ ) (Table 1S).

We performed a sensitivity analysis, by removing the 6 women who stopped endocrine therapy during the study. $\mathrm{PH}$ evolution was no longer significant $(p=0.08)$. However, improvement of Ditrovie score and FSFI total score remained significant. Figure $1 \mathrm{~S}$ and $2 \mathrm{~S}$ represent FSFI score evolution over time according to endocrine therapy (yes/ never) and chemotherapy (yes/no). No particular pattern of FSFI score evolution appeared according to these breast cancer therapies.

\section{Treatment side effects}

No serious adverse effect directly linked to laser therapy was recorded during the study period. Main minor adverse effects were discomfort grade $1(n=3)$ and small vaginal bleeding $(n=3)$ during the day after laser therapy.

During follow-up, three women had abnormal pap smear results: two had low-grade squamous intraepithelial lesions (LSIL), and one ultimately developed a highgrade squamous intraepithelial lesion (HSIL), which was 
Table 1 Characteristics of the 46 women included, at inclusion and at last laser session (i.e. 2 months)

\begin{tabular}{|c|c|c|}
\hline Characteristics & At inclusion & $\begin{array}{l}\text { At last laser } \\
\text { session (i.e. } \\
2 \text { months) }\end{array}$ \\
\hline Age (median [IQR]) & $56[45-59]$ & - \\
\hline \multicolumn{3}{|l|}{ Menopause (n, \%) } \\
\hline Natural & $29(63.0 \%)$ & \\
\hline Treatment-induced & $17(37.0 \%)$ & \\
\hline Type of breast cancer (n, \%) & & - \\
\hline Localized & $43(93.5 \%)$ & \\
\hline Metastatic & $3(6.5 \%)$ & \\
\hline Ever received chemotherapy (n, \%) & $33(71.7 \%)$ & - \\
\hline Endocrine therapy during the study (n, \%) & $36(78.2 \%)$ & - \\
\hline Type of endocrine therapy (n, \%) & & - \\
\hline Tamoxifen & $6(16.7 \%)$ & \\
\hline Aromatase inhibitor & $24(66.6 \%)$ & \\
\hline Aromatase inhibitor + LHRH agonist & $6(16.7 \%)$ & \\
\hline History of abnormal pap smear before the study ${ }^{a}$ & & - \\
\hline Yes & $2(4.3 \%)$ & \\
\hline No & $46(95.7 \%)$ & \\
\hline Vaginal $\mathrm{pH}$ & $7.0[5.8-7.0]$ & $7.0[5.8-7.0]$ \\
\hline Missing & 6 & 3 \\
\hline \multicolumn{3}{|l|}{ Epithelial maturation pattern on pap smear (n, \%) } \\
\hline Atrophy & $33(71.7 \%)$ & $34(73.9 \%)$ \\
\hline Subatrophy & $4(8.7 \%)$ & $3(6.5 \%)$ \\
\hline Mature & $9(19.6 \%)$ & $7(15.2 \%)$ \\
\hline Missing & 0 & 2 \\
\hline Ditrovie score (median, [IQR]) & $1.2[1.0-1.6]$ & $1.1[1.0-1.4]$ \\
\hline Missing or incomplete & 4 & 4 \\
\hline FSFI total score (median, [IQR]) & $9.5[4.3-16.2]$ & $20.5[14.0-25.2]$ \\
\hline Missing or incomplete & 6 & 9 \\
\hline SF12 mental component score (median, [IQR]) & $40.6[33.8-50.5]$ & $39.6[34.3-49.9]$ \\
\hline Missing or incomplete & 5 & 12 \\
\hline SF12 physical component score (median, [IQR]) & $40.6[35.1-47.0]$ & 42.0 [38.8-51.9] \\
\hline Missing or incomplete & 5 & 12 \\
\hline
\end{tabular}

FSFI Female sexual function index, IQR interquartile range

${ }^{a}$ The 2 women had history of low-grade cervical lesions but with normal follow-up since several years before the study removed by loop excision. None of these women had history of abnormal pap smear before the study. The woman who developed HSIL was 49 years old at study entry and had a prior smoking history. She had de novo metastatic breast cancer since September 2017, treated with CDK4/6 inhibitor (palbociclib) and endocrine therapy. The pap smear performed 6 months after last laser therapy showed atypical squamous cells that cannot exclude HSIL (ASCH). First biopsy only found cervicitis. Control pap smear at 1 year (according to the French recommendations) turned into HSIL with a positive high-risk HPV test (HPV 31/35/33/52/58) and biopsy confirmed high-grade lesion. Loop excision found junctional high-grade intraepithelial lesion of $4 \mathrm{~mm}$ with healthy margins. Another woman, aged 44 and current smoker, had ASC-H pap smear at the last laser session. Colposcopy found low-grade lesions and high-risk HPV test was positive (no HPV typing). Control pap smear and colposcopy at 6 months were normal. Eighteen months after first HPV test, pap smear was normal and high-risk HPV test turned negative. The last women, aged 43 and non-smoking, had atypical squamous cells of undetermined signification (ASCUS) on pap smear 11 months after the last laser session. Biopsy found a lowgrade lesion but high-risk HPV test was negative. Control pap smear one year later was normal. It should be noted that HPV testing as primary screening was not recommended in France at the beginning of the study. 


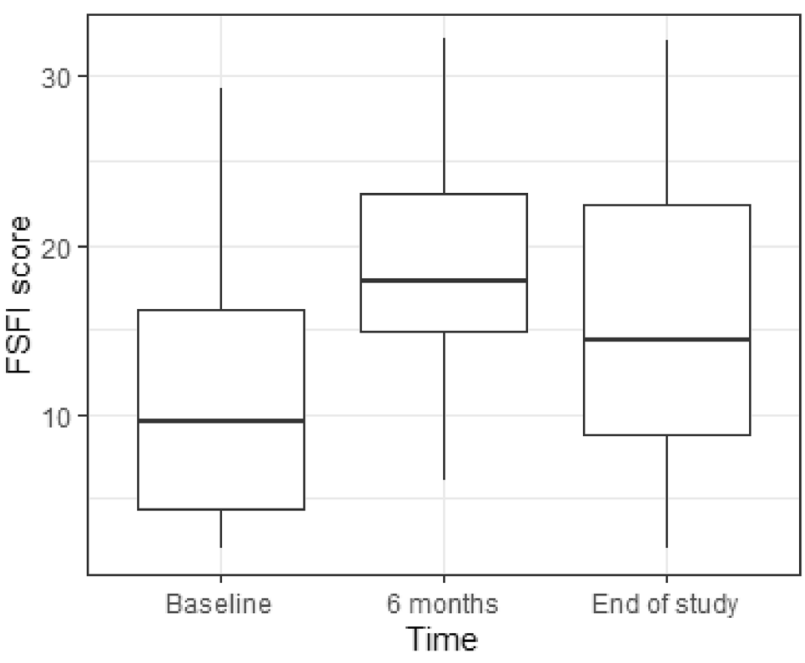

Fig. 2 Evolution of FSFI total score over time (boxplot)

\section{Discussion}

Vaginal laser therapy for the treatment of GSM and VVA in women with breast cancer is effective with an improvement of sexual quality of life and urinary function, which is the ultimate objective, although global quality of life and objective measurements with $\mathrm{pH}$ level and epithelial maturation pattern on pap smear did not change.
Improvement was highest at 2 months after laser session for sexual quality of life and 6 months for urinary quality of life, then decreased but remained above baseline score for sexual function.

While most of laser therapy studies included women with various causes of VVA (with or without cancer), this study is, to our knowledge, one of the largest prospective cohort of women with BC treated for VVA with laser therapy. It is also one of the few studies to follow women with BC up to 18 months after laser therapy [19], whereas most of prior studies assessed laser efficacy at 1 or 3 months. To date, no results of randomized studies assessing vaginal laser therapy in breast cancer survivors are yet available. Several randomized trials are ongoing, which assess vaginal laser therapy versus placebo (sham laser) or local treatment, among women with breast cancer (such as: NCT04619485, NCT04517370, NCT04081805, NCT04606550).

Our results are similar to those of a recent cohort study in $\mathrm{BC}$ women treated with $\mathrm{CO}_{2}$ laser therapy, where FSFI score improved in the same magnitude, and with changes remaining 12 months after laser therapy [28]. Of note, three randomized studies [29-31] comparing laser therapy versus local hormonal therapy or a combination of both in postmenopausal women without breast cancer revealed that laser therapy and local hormonal therapy had similar efficacy on VVA symptoms, with improvement of FSFI scores in all of them.
Fig. 3 Evolution of FSFI total score over time (per woman)

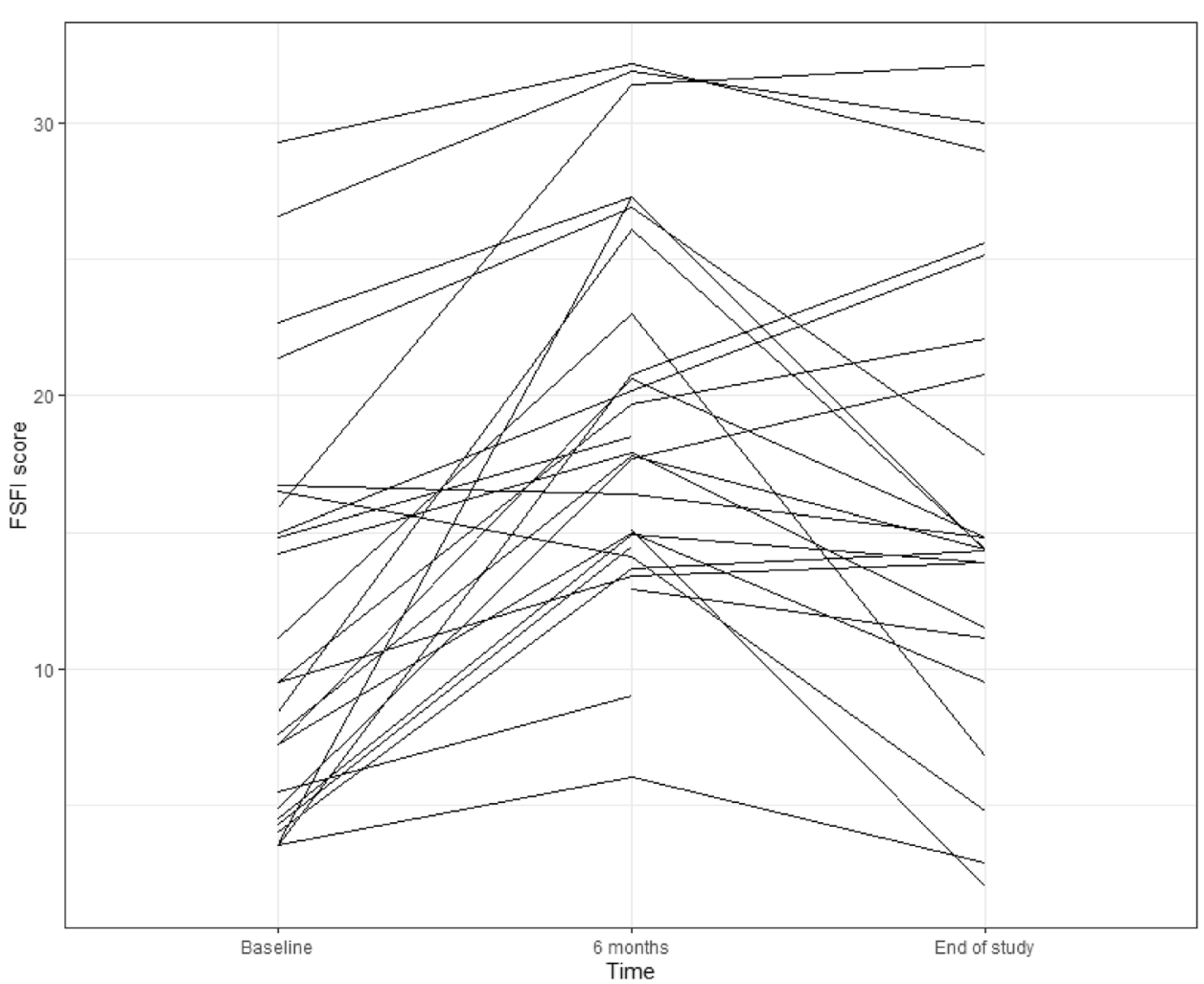


Table 2 Evolution of each FSFI domain score over time

\begin{tabular}{lllll}
\hline $\begin{array}{l}\text { FSFI score domains } \\
\text { (median, IQR) }\end{array}$ & Baseline & 2 months & 6 months & End of study \\
\hline Arousal & $1.5[0.3-2.8]$ & $3.1[1.9-4.5]$ & $3.0[2.2-4.5]$ & $2.7[0.75-4.5]$ \\
Missing & 2 & 4 & 11 & 11 \\
Desire & $2.4[1.2-3.0]$ & $2.7[1.8-3.6]$ & $2.7[1.8-3.6]$ & $2.4[1.2-3.6]$ \\
Missing & 2 & 4 & 10 & 10 \\
Pain & $1.2[0-2.0]$ & $2.0[0-4.4]$ & $2.8[0.9-3.7]$ & $1.2[0-2.6]$ \\
Missing & 2 & 6 & 10 & 10 \\
Lubrication & $1.2[0-2.1]$ & $3.6[1.5-4.8]$ & $3.3[1.8-4.6]$ & $2.7[0-3.7]$ \\
Missing & 3 & 5 & 11 & 10 \\
Orgasm & $1.6[0-3.2]$ & $3.2[1.2-4.8]$ & $2.8[1.4-4.2]$ & $2.8[0.4-4.2]$ \\
Missing & 3 & 6 & 11 & 11 \\
Satisfaction & $2.4[1.2-4.0]$ & $3.8[2.7-4.9]$ & $4.0[3.2-4.8]$ & $3.6[1.5-4.8]$ \\
Missing & 5 & 6 & 16 & 14 \\
\hline
\end{tabular}

FSFI Female sexual function index
Fig. 4 Evolution of Ditrovie score over time (per woman)

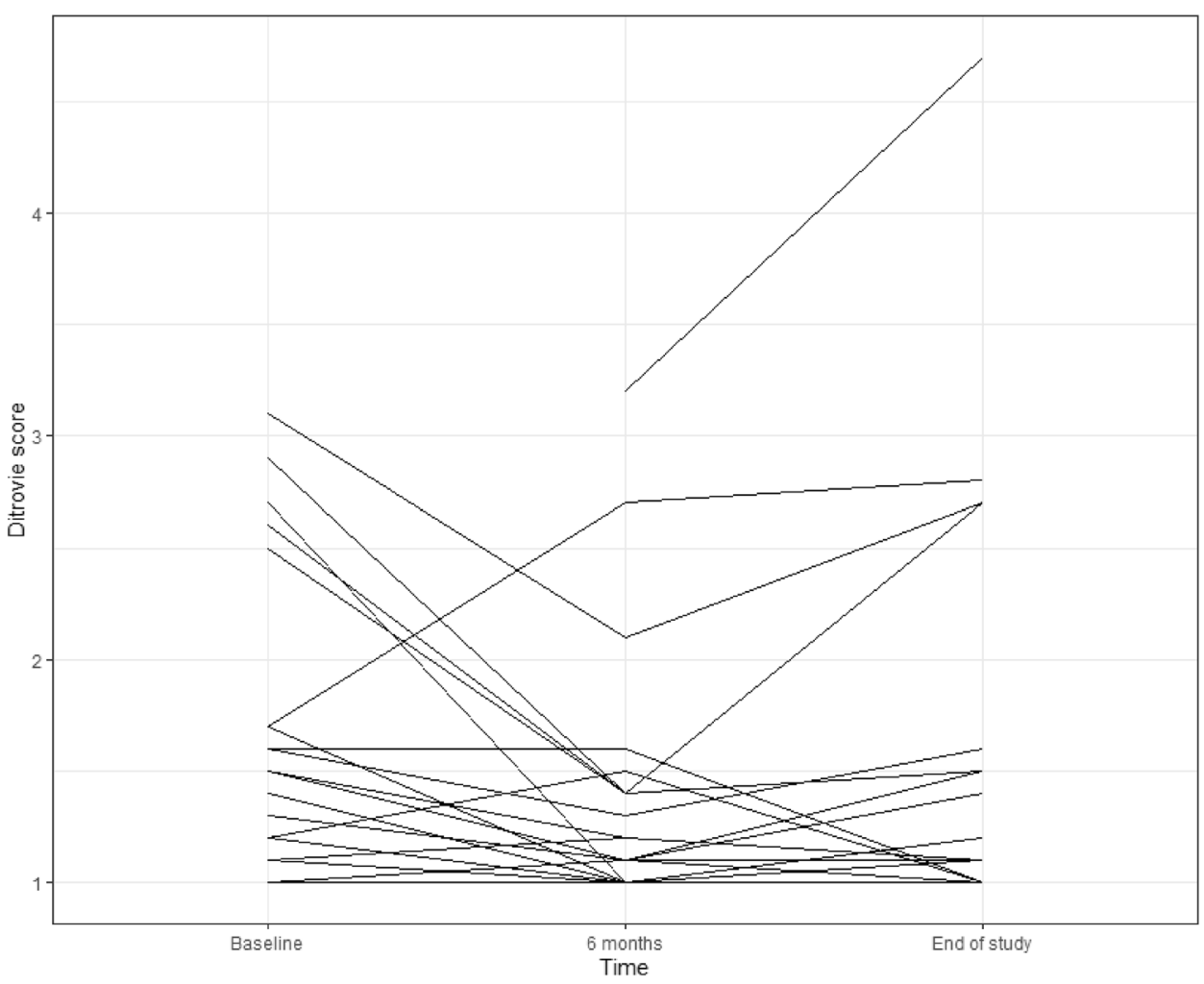

Using regular pap smear assessments enabled us to detect three women who developed squamous intraepithelial cervical lesions during the follow-up. None of them had known high-risk HPV infection before the study or history of abnormal pap smear, since HPV testing was not recommended in France at the time of the study. The two women who had high-risk HPV were also heavy smokers, which is a known risk factor of persistent HPV infection. Both women with LSIL received chemotherapy for BC treatment, but it was stopped 4 and 10 years before study entry. The women who developed HSIL were treated with
CDK4/6 inhibitor palbociclib, which can decrease white cells count and modify immune system efficacy. Although a known risk factor of persistent HPV infection is immunodeficiency, we found no data on the incidence of positive HPV tests and intraepithelial cervical lesions after the treatment of breast cancer, including chemotherapy or targeted therapy like CDK4/6 inhibitors. To our knowledge, there are no data on a potential link between vaginal laser therapy and HPV infection, and no other study described intraepithelial lesions after laser therapy. A role of the present laser therapy cannot be ruled out in the 
emergence of HPV-linked lesions in 3 participants in this study. Laser efficacy can also foster new intercourse and so, new HPV infection [32]. Although no causal effect with either treatment can be demonstrated, it would be interesting in further studies to investigate a potential link between laser and HPV infection or HPV-induced cervical lesions. However, while waiting for these studies, women should have recent negative high-risk HPV test before beginning vaginal laser therapy.

Other therapies are being tested to treat vaginal dryness among women with BC. Vaginal dehydroepiandrosterone (DHEA) has been approved in USA and in Europe for the treatment of VVA in healthy postmenopausal women. A recent randomized study comparing vaginal DHEA versus lubricant in BC women showed improved FSFI scores in the high-dose DHEA group [33]. Systemic estradiol level was higher in those with high-dose DHEA but not among women taking aromatase inhibitors [34]. To date, vaginal DHEA has not been approved yet for breast cancer survivors, in the absence of safety studies.

Our study has some limitations. First, it was a single-centred non-randomized study; thus, biases in population selection and results cannot be ruled out. Some $\mathrm{pH}$ measurements could have been affected by the technical procedures (using soap for gynaecological examination). As soap has basic $\mathrm{pH}$, it could have increased $\mathrm{pH}$ values. Since most practitioners probably used soap during the study, $\mathrm{pH}$ measurements must have been affected for the vast majority of participants. Thus, this bias is likely to be non-differential. We did not assess vaginal trophicity, but only specified the maturation pattern on the cervical pap test, unlike most of laser studies which evaluated vaginal trophicity using vaginal maturity index on vaginal walls [29-31]. Thus, our results on cervical maturation pattern cannot be compared to others. This could partly explain why no cervical epithelial lesion has ever been described in laser studies, as they did not specifically used cervical pap smear in the follow-up. Moreover, only a few women had altered urinary quality of life at inclusion ( 7 women with Ditrovie total score $\geq 2$ ), limiting results interpretation. FSFI score use requires that women have engaged in sexual activity and have attempted vaginal penetration over the past 4 weeks [26]. In our study, based on FSFI responses, only 29 women $(63 \%)$ had had sex in the last 4 weeks at inclusion, reflecting that sexual dysfunction is common after breast cancer [35] or that some women may also not be involved in a relationship. That could explain why FSFI score could be lower than expected, as some FSFI domains cannot be properly evaluated (such as pain, lubrication and orgasm). Thus, efficacy of laser therapy on FSFI score could be underestimated. A FSFI score adapted to women with breast cancer, measuring distress and changes after cancer, would be of better interest for further studies [36]. Finally, our cohort included only 46 women. Although it is one of the largest studies among women with breast cancer, subgroup analyses were thus only exploratory.

In conclusion, this study evaluating laser efficacy on VVA among women with breast cancer, one of the largest on this topic, showed that laser therapy increased sexual function and urinary function with long-term effects up to 18 months after treatment, although the observed effect decreased after 6 months. Further studies should investigate the required number of initial laser sessions ( 3 or 4 ) and duration until maintenance laser session [20], as well as compare nonhormonal local treatment versus laser therapy. Finally, the effects of vaginal laser therapy on risk of HPV infection is yet unknown. Therefore, laser should be used with caution with women with HPV history and women should have recent negative high-risk HPV test before beginning vaginal laser therapy.

Supplementary Information The online version contains supplementary material available at https://doi.org/10.1007/s10549-021-06226-3.

Acknowledgements We thank Drs Mimoun and Mouly who helped us implement vaginal laser therapy in our hospital.

Author contributions Study conception and design were performed by DW with the help of PP and SD. Material preparation and data collection were performed by DW, GA and LV. Pap smears were evaluated by VS. Analysis was performed by LV and DC. The first draft of the manuscript was written by LV and all authors commented on previous versions of the manuscript. All authors read and approved the final manuscript.

Funding Not applicable.

Data availability The datasets generated during and analysed during the current study are available from the corresponding author on reasonable request.

\section{Declarations}

Conflict of interest The microablative laser was provided by DEKA. There was no financial support from DEKA.

Ethical approval This study has been approved by a French Ethics Committee (2018-A01500-55).

Consent to participate All participants gave oral consent to the study.

\section{References}

1. Bray F, Ferlay J, Soerjomataram I, Siegel RL, Torre LA, Jemal A (2018) Global cancer statistics 2018: GLOBOCAN estimates of incidence and mortality worldwide for 36 cancers in 185 countries. CA Cancer J Clin 68:394-424. https://doi.org/10.3322/caac. 21492

2. Streicher L, Simon JA (2018) Sexual function post-breast cancer. Cancer Treat Res 173:167-189. https://doi.org/10.1007/978-3319-70197-4_11 
3. Baumgart J, Nilsson K, Evers AS, Kallak TK, Poromaa IS (2013) Sexual dysfunction in women on adjuvant endocrine therapy after breast cancer. Menopause 20:162-168. https:// doi.org/10.1097/gme.0b013e31826560da

4. Goss PE, Ingle JN, Martino S, Robert NJ, Muss HB, Piccart MJ et al (2005) Randomized trial of letrozole following tamoxifen as extended adjuvant therapy in receptor-positive breast cancer: updated findings from NCIC CTG MA17. J Natl Cancer Inst 97:1262-1271. https://doi.org/10.1093/jnci/dji250

5. Jakesz R, Greil R, Gnant M, Schmid M, Kwasny W, Kubista E et al (2007) Extended adjuvant therapy with anastrozole among postmenopausal breast cancer patients: results from the randomized Austrian breast and colorectal cancer study group trial 6a. J Natl Cancer Inst 99:1845-1853. https://doi.org/10.1093/ jnci/djm246

6. Dowsett M, Cuzick J, Ingle J, Coates A, Forbes J, Bliss J et al (2010) Meta-analysis of breast cancer outcomes in adjuvant trials of aromatase inhibitors versus tamoxifen. J Clin Oncol Off J Am Soc Clin Oncol 28:509-518. https://doi.org/10.1200/JCO. 2009.23.1274

7. Koga C, Akiyoshi S, Ishida M, Nakamura Y, Ohno S, Tokunaga E (2017) Chemotherapy-induced amenorrhea and the resumption of menstruation in premenopausal women with hormone receptor-positive early breast cancer. Breast Cancer Tokyo Jpn 24:714-719. https://doi.org/10.1007/s12282-017-0764-1

8. Fallowfield L, Cella D, Cuzick J, Francis S, Locker G, Howell A (2004) Quality of life of postmenopausal women in the arimidex, tamoxifen, alone or in combination (ATAC) adjuvant breast cancer trial. J Clin Oncol 22:4261-4271. https://doi.org/ 10.1200/JCO.2004.08.029

9. Oberguggenberger A, Martini C, Huber N, Fallowfield L, Hubalek M, Daniaux M et al (2017) Self-reported sexual health: breast cancer survivors compared to women from the general population - an observational study. BMC Cancer 17:599. https://doi.org/10.1186/s12885-017-3580-2

10. Hawkins Y, Ussher J, Gilbert E, Perz J, Sandoval M, Sundquist $\mathrm{K}$ (2009) Changes in sexuality and intimacy after the diagnosis and treatment of cancer: the experience of partners in a sexual relationship with a person with cancer. Cancer Nurs 32:271280. https://doi.org/10.1097/NCC.0b013e31819b5a93

11. Pistilli B, Paci A, Ferreira AR, Di Meglio A, Poinsignon V, Bardet A et al (2020) Serum detection of nonadherence to adjuvant tamoxifen and breast cancer recurrence risk. J Clin Oncol Off J Am Soc Clin Oncol. https://doi.org/10.1200/JCO.19.01758

12. Santen RJ, Stuenkel CA, Davis SR, Pinkerton JV, Gompel A, Lumsden MA (2017) Managing menopausal symptoms and associated clinical issues in breast cancer survivors. J Clin Endocrinol Metab 102:3647-3661. https://doi.org/10.1210/jc. 2017-01138

13. Salvatore S, Nappi RE, Zerbinati N, Calligaro A, Ferrero S, Origoni $\mathrm{M}$ et al (2014) A 12-week treatment with fractional CO2 laser for vulvovaginal atrophy: a pilot study. Climacteric J Int Menopause Soc 17:363-369. https://doi.org/10.3109/13697137. 2014.899347

14. Pieralli A, Bianchi C, Longinotti M, Corioni S, Auzzi N, Becorpi A et al (2017) Long-term reliability of fractioned CO2 laser as a treatment for vulvovaginal atrophy (VVA) symptoms. Arch Gynecol Obstet 296:973-978. https://doi.org/10.1007/ s00404-017-4504-8

15. Gambacciani M, Levancini M, Russo E, Vacca L, Simoncini T, Cervigni M (2018) Long-term effects of vaginal erbium laser in the treatment of genitourinary syndrome of menopause. Climacteric J Int Menopause Soc 21:148-152. https://doi.org/10.1080/ 13697137.2018.1436538

16. Ruanphoo P, Bunyavejchevin S (2020) Treatment for vaginal atrophy using microablative fractional $\mathrm{CO} 2$ laser: a randomized double-blinded sham-controlled trial. Menopause N Y N. https:// doi.org/10.1097/GME.0000000000001542

17. Pagano T, De Rosa P, Vallone R, Schettini F, Arpino G, De Placido $S$ et al (2016) Fractional microablative CO2 laser for vulvovaginal atrophy in women treated with chemotherapy and/or hormonal therapy for breast cancer: a retrospective study. Menopause N Y N 23:1108-1113. https://doi.org/10.1097/GME.0000000000 000672

18. Quick AM, Zvinovski F, Hudson C, Hundley A, Evans C, Suresh A et al (2019) Fractional CO2 laser therapy for genitourinary syndrome of menopause for breast cancer survivors. Support Care Cancer Off J Multinatl Assoc Support Care Cancer. https://doi. org/10.1007/s00520-019-05211-3

19. Gambacciani M, Levancini M (2017) Vaginal erbium laser as second-generation thermotherapy for the genitourinary syndrome of menopause: a pilot study in breast cancer survivors. Menopause 24:316-319. https://doi.org/10.1097/GME.0000000000000761

20. Tranoulis A, Georgiou D, Michala L (2019) Laser treatment for the management of genitourinary syndrome of menopause after breast cancer. Hope or hype? Int Urogynecology J 30:1879-1886. https://doi.org/10.1007/s00192-019-04051-3

21. Jha S, Wyld L, Krishnaswamy PH (2019) The impact of vaginal laser treatment for genitourinary syndrome of menopause in breast cancer survivors: a systematic review and meta-analysis. Clin Breast Cancer 19:e556-e562. https://doi.org/10.1016/j.clbc. 2019.04.007

22. Nayar R, Wilbur D (2015) The bethesda system for reporting cervical cytology: definitions criteria and explanatory notes, 3rd edn. Springer International Publishing, Cham. https://doi.org/10.1007/ 978-3-319-11074-5

23. Kocjan G, Gray W, Levine T, Kardum-Skelin I, Vielh P (2013) Diagnostic cytopathology essentials. Elsevier, Amsterdam

24. Ware J, Kosinski M, Keller SD (1996) A 12-Item short-form health survey: construction of scales and preliminary tests of reliability and validity. Med Care 34:220-233. https://doi.org/10. 1097/00005650-199603000-00003

25. Baser RE, Li Y, Carter J (2012) Psychometric validation of the female sexual function index (FSFI) in cancer survivors. Cancer 118:4606-4618. https://doi.org/10.1002/cncr.26739

26. Meston CM, Freihart BK, Handy AB, Kilimnik CD, Rosen RC (2020) Scoring and Interpretation of the FSFI: what can be learned from 20 years of use? J Sex Med 17:17-25. https://doi. org/10.1016/j.jsxm.2019.10.007

27. Amarenco G, Marquis P, Leriche B, Richard F, Zerbib M, Jacquetin B (1997) Une échelle spécifique d'évaluation de la perturbation de la qualité de vie au cours des troubles mictionnels: l'échelle Ditrovie. Ann Réadapt Médecine Phys 40:21-26. https://doi.org/ 10.1016/S0168-6054(97)85882-5

28. Quick AM, Zvinovski F, Hudson C, Hundley A, Evans C, Stephens JA et al (2021) Patient-reported sexual function of breast cancer survivors with genitourinary syndrome of menopause after fractional CO2 laser therapy. Menopause. https://doi.org/10.1097/ GME.0000000000001738

29. Cruz VL, Steiner ML, Pompei LM, Strufaldi R, Fonseca FLA, Santiago LHS et al (2018) Randomized, double-blind, placebocontrolled clinical trial for evaluating the efficacy of fractional $\mathrm{CO} 2$ laser compared with topical estriol in the treatment of vaginal atrophy in postmenopausal women. Menopause 25:21-28. https://doi.org/10.1097/GME.0000000000000955

30. Politano CA, Costa-Paiva L, Aguiar LB, Machado HC, Baccaro LF (2019) Fractional CO2 laser versus promestriene and lubricant in genitourinary syndrome of menopause: a randomized clinical trial. Menopause 26:833-840. https://doi.org/10.1097/GME. 0000000000001333

31. Paraiso MFR, Ferrando CA, Sokol ER, Rardin CR, Matthews CA, Karram MM et al (2020) A randomized clinical trial comparing 
vaginal laser therapy to vaginal estrogen therapy in women with genitourinary syndrome of menopause: the VeLVET trial. Menopause 27:50-56. https://doi.org/10.1097/GME.0000000000 001416

32. Bosch FX, Burchell AN, Schiffman M, Giuliano AR, de Sanjose S, Bruni L et al (2008) Epidemiology and natural history of human papillomavirus infections and type-specific implications in cervical neoplasia. Vaccine 26(Suppl 10):K1-16. https://doi.org/ 10.1016/j.vaccine.2008.05.064

33. Barton DL, Sloan JA, Shuster LT, Gill P, Griffin P, Flynn K et al (2018) Evaluating the efficacy of vaginal dehydroepiandosterone for vaginal symptoms in postmenopausal cancer survivors: NCCTG N10C1 (Alliance). Support Care Cancer Off J Multinatl Assoc Support Care Cancer 26:643-650. https://doi.org/10.1007/ s00520-017-3878-2

34. Barton DL, Shuster LT, Dockter T, Atherton PJ, Thielen J, Birrell SN et al (2018) Systemic and local effects of vaginal dehydroepiandrosterone (DHEA): NCCTG N10C1 (Alliance). Support Care Cancer Off J Multinatl Assoc Support Care Cancer 26:1335-1343. https://doi.org/10.1007/s00520-017-3960-9

35. Broeckel JA, Thors CL, Jacobsen PB, Small M, Cox CE (2002) Sexual functioning in long-term breast cancer survivors treated with adjuvant chemotherapy. Breast Cancer Res Treat 75:241-248

36. Bartula I, Sherman KA (2015) Development and validation of the female sexual function Index adaptation for breast cancer patients (FSFI-BC). Breast Cancer Res Treat 152:477-488. https://doi.org/ 10.1007/s10549-015-3499-8

Publisher's Note Springer Nature remains neutral with regard to jurisdictional claims in published maps and institutional affiliations. 